22.1

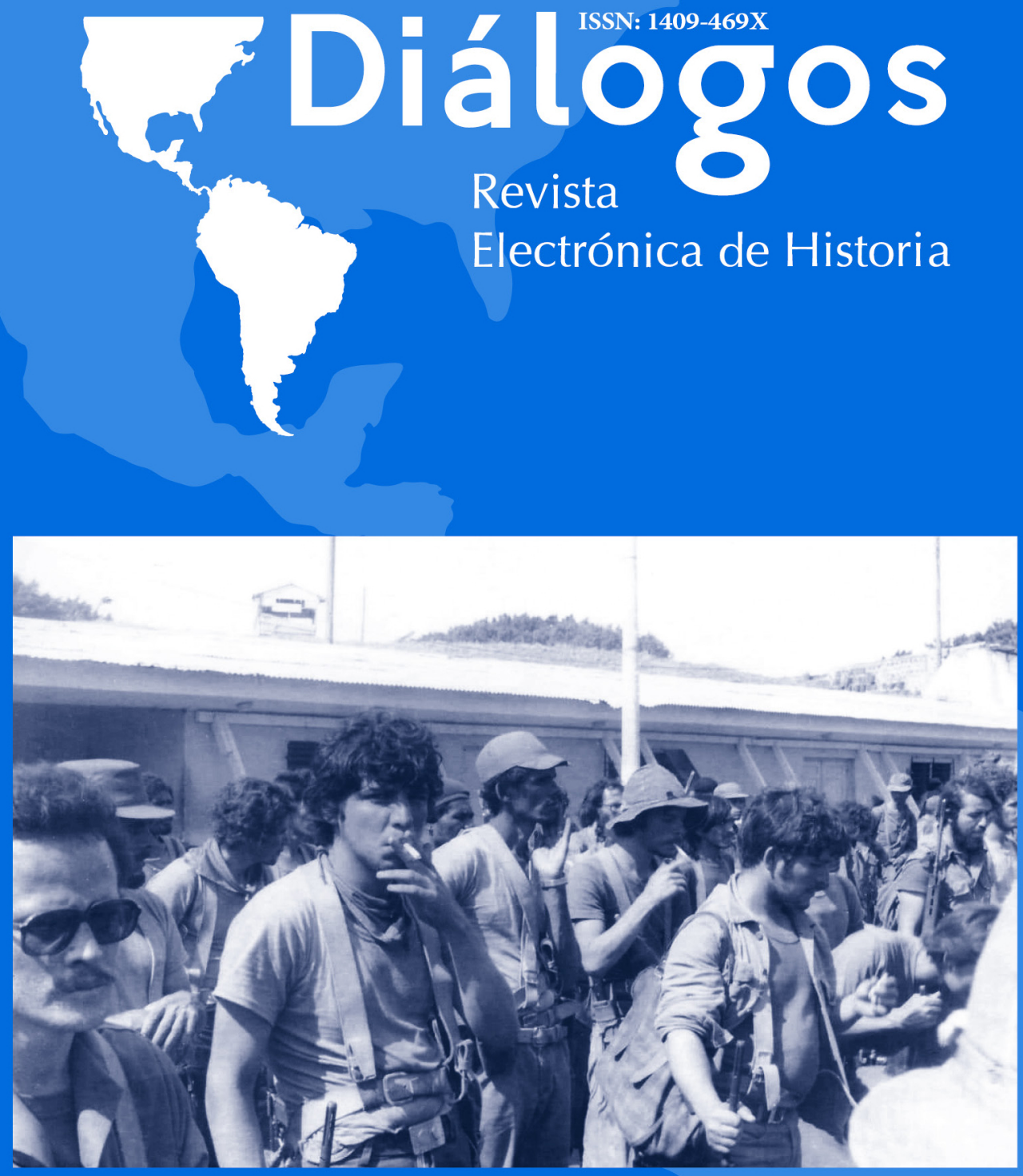

Centro de Investigaciones Históricas de América Central. Universidad de Costa Rica

\title{
Enero-junio 2021
}

url: http://revistas.ucr.ac.cr/index.php/dialogos/index 


\title{
“AVENTUREROS PEQUEÑO-BURGUESES” Y "LA VIEJA GENERACIÓN REVOLUCIONARIA": EL FSLN Y EL PVP (1966-1970)
}

Sofía Cortés Sequeira

\begin{abstract}
Resumen
El objetivo principal de este artículo es analizar las relaciones entre las direcciones políticas del PVP y del FSLN en la década de 1960, a partir de la correspondencia sostenida entre Manuel Mora Valverde y Carlos Fonseca Amador, para poder identificar las contradicciones, discrepancias y coincidencias entre los dirigentes de ambas organizaciones: la primera de corte comunista y, la segunda, una guerrilla nacionalista nacida bajo la impronta del modelo cubano. En este sentido, se parte de la interrogante de cómo fueron las relaciones entre el Partido Vanguardia Popular (PVP) y el Frente Sandinista de Liberación Nacional (FSLN) durante la década de 1960, siendo ambas organizaciones de naturaleza distinta y mantenido líneas políticas diferentes sobre la estrategia a seguir en la lucha antisomocista.
\end{abstract}

Como hipótesis central se sostiene que el establecimiento de relaciones entre ambas organizaciones fue un proceso complejo, marcado por desconfianzas y diferencias mutuas, arrastradas desde la fundación misma del FSLN hacia finales de la década de 1960, ya que ambas eran expresión de dos corrientes revolucionarias distintas, que en todo el continente discrepaban en función de las vías y estrategias para combatir a los regímenes dictatoriales que dominaban la región.

Palabras clave: izquierdas, comunistas, guerrilla, sandinistas, revolución. 


\title{
“PETTY-BOURGEOIS ADVENTURERS” AND “THE OLD REVOLUTIONARY GENERATION": THE FSLN AND THE PVP (1966-1970)
}

\begin{abstract}
The main objective of this article is to analyze the relationships between the political leadership of the PVP and the FSLN in the 1960s, based on the correspondence between Manuel Mora Valverde and Carlos Fonseca Amador, in order to identify the contradictions, discrepancies and coincidences between the leaders of both organizations: the first a communist and the second a nationalist guerrilla born under the imprint of the Cuban model. In this sense, the article starts from the question of how the relations between the Partido Vanguardia Popular (PVP) and the Frente Sandinista de Liberación Nacional (FSLN) were during the 1960s, in which both organizations had a different nature and maintained different political lines on the strategy to follow in the antisomocista fight.

As a central hypothesis, the article maintains that the establishment of relations between both organizations was a complex process, marked by mistrust and mutual differences and dragged from the very foundation of the FSLN towards the end of the 1960s. Moreover these relations were the expression of two different revolutionary currents that throughout the continent disagreed based on the ways and strategies to combat the dictatorial regimes that dominated the region.
\end{abstract}

Keywords: lefts, communists, guerrillas, sandinistas, revolution. 


\section{EL PVP Y EL FSLN EN LAS DÉCADAS DE 1960 Y 1970.}

Para adentrarse en el período y objeto de estudio, es necesario, en primer lugar, tener presente el panorama de las organizaciones de izquierda a nivel regional en las décadas de 1960 y 1970, partiendo de la caracterización general del FSLN como un movimiento político-militar y del PVP como un partido comunista. En este sentido, la década de 1960 vio nacer a lo largo y ancho de toda América Latina una serie de movimientos político-militares organizados bajo la forma de frentes guerrilleros que, bajo la influencia del triunfo revolucionario cubano de 1959, optaron por priorizar la estrategia armada frente a la opción político electoral para combatir a los regímenes dictatoriales que dominaban el panorama político de la región. Estas organizaciones criticaron las estrategias y premisas de los partidos comunistas ligados al modelo soviético, que habían sido fundados en su mayoría en las décadas de 1930 y 1940 (Figueroa y I Puig, 2006).

Desde la década de 1940, en el marco de la lucha global contra el fascismo, la línea desarrollada por los partidos comunistas latinoamericanos había sido la coexistencia pacífica o los también llamados Frentes Populares, que privilegiaba la formación y consecución de alianzas con sectores progresistas y democráticos de las burguesías nacionales que se opusieran a las fuerzas imperialistas para abrir la posibilidad de conseguir gobiernos menos represivos, lo que llevó a la moderación de sus estrategias y discursos. Su apuesta política era la consecución de democracias representativas como condición necesaria para la maduración de las fuerzas populares en la región, por lo que siempre privilegiaron la vía electoral, sumándose a alianzas explícitas o implícitas con sectores moderados del espectro político (Figueroa y I Puig, 2006). Estos buscaban lograr en sus países una revolución "democrático-burguesa" y planteaban la necesidad de conseguir una reforma agraria que permitiera el desarrollo de un mercado nacional que impulsara y dinamizara las economías nacionales, condición esencial para liberarse del "yugo imperialista" (Gould, 2009, p. 350).

Es en la década de 1960, que bajo la impronta cubana surgió la llamada "nueva izquierda" compuesta por una generación de jóvenes radicalizados provenientes en su mayoría de sectores urbanos de clase media y universitarios. Estos criticaron y rompieron con la estrategia anterior, abandonando las filas de los partidos comunistas, emprendiendo una crítica contra la moderación en que habían caído dichas organizaciones y planteando la necesidad de luchar por una revolución socialista en el corto plazo. En reacción a la ofensiva estadounidense desatada en la región posterior a la revolución cubana, estos jóvenes descartaron la posibilidad de un camino pacífico hacia el socialismo, tal como lo proponían los partidos comunistas, quienes dejaron de ser la única o principal referencia revolucionaria. De esta manera, las fuerzas revolucionarias latinoamericanas se dividieron alrededor del concepto y las vías de la revolución. (Gould, 2009). 
En este sentido, para Eduardo Rey Tristán (2016, pp.363-368) estas organizaciones de la llamada "nueva izquierda" latinoamericana definieron su idea de revolución, haciendo referencia fundamentalmente a las formas, métodos o vías para lograr la transformación social y específicamente a la lucha armada e independientemente de la existencia de un proyecto político, social o económico claro para llevar adelante.

Este contexto, a la par de un aumento de la represión estatal, hizo posible que esta década viera nacer a las primeras organizaciones guerrilleras centroamericanas, donde el Frente Sandinista de Liberación Nacional (FSLN), fundado en 1961, fue la primera en su tipo (Figueroa y I Puig, 2006). Estas eran por lo general organizaciones pequeñas y altamente jerárquicas que se preocuparon por desarrollar una tarea concreta: la lucha armada para la toma del poder estatal (Figueroa y I Puig, 2006).

Como señala Torres-Rivas (2008), la reacción de los partidos comunistas frente al surgimiento de estas organizaciones no se hizo esperar. Estos criticaron, rechazaron y se distanciaron de los métodos y estrategias de lucha guerrillera, catalogándolas como "aventurerismo pequeño burgués", lo que generó una tensa relación entre ambas expresiones organizativas. No obstante, en la década de 1970, la discusión sobre el apoyo o no a la estrategia guerrillera terminó dividiendo, disolviendo o incorporando a la lucha armada a los diferentes partidos comunistas centroamericanos conforme esta pasó a generar un mayor consenso como vía para terminar con los regímenes autoritarios que dominaban la región, especialmente a partir del triunfo sandinista en 1979. Esto generó que, para inicios de la década de 1980, la mayoría de los partidos comunistas en Centroamérica existieran ya de manera precaria o testimonial, luego de divisiones o disoluciones en los frentes guerrilleros.

En Costa Rica, la influencia del proceso revolucionario cubano se hizo sentir en el surgimiento de organizaciones políticas de la llamada nueva izquierda, que se posicionaron críticamente frente al Partido Vanguardia Popular (PVP), partido comunista histórico. Así, a mediados de la década de 1960, un grupo de jóvenes en su mayoría perteneciente a sectores medios urbanos e intelectuales radicalizados fundaron el Partido Revolucionario Auténtico (PRA), que a finales de la década pasó a llamarse Movimiento Revolucionario Auténtico (MRA). Alberto Salom (1987), quien fue militante del Partido Socialista Costarricense, indica que este se planteó en sus inicios como un movimiento político militar que privilegiaba la estrategia armada por sobre la estrategia político electoral, influenciado por el Movimiento 26 de Julio en Cuba y el naciente FSLN en Nicaragua. La revolución socialista y la toma del poder se vislumbraron como una tarea en el corto plazo. No obstante, sus planteamientos chocaron de frente con una Costa Rica que poco se parecía a la Cuba de Fulgencio Batista o la Nicaragua de los Somoza y que no dejaba campo para el impulso de una lucha armada en el país. En este sentido, como indican Molina y Díaz (2017), en Costa Rica el anticomunismo practicado durante las primeras décadas de la Guerra Fría (1948-1979) tomó cauces reformistas, por lo que a la par de un amplio despliegue ideológico anticomunista se desarrolló una robusta política social destinada a arrebatarle las banderas y reivindicaciones propias a la izquierda política. 
De esta manera, si bien la represión fue ejercida en varios momentos, no fue el elemento central para la "contención del comunismo" en el país.

Así, el PRA se mantuvo como una organización pequeña dentro del espectro político de izquierdas, aun cuando en la década de 1970 experimentó cierto crecimiento cuantitativo y un desarrollo entre sectores estudiantiles universitarios, que se abocaron a desarrollar un trabajo político entre organizaciones campesinas del Valle Central y Guanacaste. En este período, cambiaron su nombre a Movimiento Revolucionario del Pueblo (MRP), y hacia 1977 realizaron su primer congreso ideológico. Para este momento, organizativamente se habían configurado más como partido político que como un movimiento armado y su discurso se había moderado conforme profundizaron el trabajo político con sectores sociales costarricenses. Por sus características organizativas e ideológicas desde su fundación, esta organización empezó a colaborar de manera activa con el FSLN. Por otro lado, en 1972 se fundó el Partido Socialista Costarricense (PSC), con una base social similar a la del MRP, jóvenes urbanos e intelectuales universitarios radicalizados (Salom, 1987).

Estas organizaciones fueron expresión de la llamada nueva izquierda en Costa Rica. Para Solís (1985), su principal limitante fue que no definieron sus postulados e identidad frente a la sociedad costarricense, sino frente a determinadas tesis del PVP y de la izquierda comunista, construyéndose así como alternativa frente a este partido, pero no frente a la sociedad. Asimismo, las diferencias esbozadas entre las organizaciones no se establecieron en función de una interpretación distinta de la sociedad costarricense, sino frente a postulados ideológicos que se interpretaban de manera ahistórica.

Por su parte, para el PVP la década de 1960 fue escenario de importantes discusiones, discrepancias y tensiones a raíz de la popularidad de la estrategia revolucionaria cubana, considerando especialmente problemática la promoción regional de la lucha armada en oposición a la vía pacífica. La posición del PVP frente a este escenario fue sintetizada en las resoluciones del IV Pleno del Comité Central, desarrollado el 8 y 10 de marzo de 1968 a partir del informe redactado por Manuel Mora Valverde, secretario general de la organización (Merino, 1996). En este documento, en primera instancia se reconocía que en Costa Rica no estaba a la orden del día la toma del poder por parte del PVP mas sí veían posible el ascenso de un bloque de fuerzas democráticas y patrióticas con la participación de los comunistas en él. Para esto, se planteaban como tarea de primer orden facilitar la construcción de este bloque, que debería ser capaz de defender la soberanía nacional, robustecer el régimen democrático existente amenazado por las fuerzas imperialistas, llevar adelante la reforma agraria y desarrollar la economía nacional en beneficio de la población costarricense ("Camino pacífico", 1968).

Además, consideraron que el camino de la guerra de guerrillas, en boga en la región, no era viable en el país, donde correspondía por el contrario aprovechar al máximo los caminos legales existentes para ganar las batallas de la clase trabajadora. No obstante, no descartaron en ese momento que el imperialismo y las "fuerzas de la reacción interna" eventualmente llevaran al pueblo a tener que defender al régimen democrático y la soberanía nacional con las armas ("Camino pacífico", 1968). 
En cuanto a las fuerzas motrices del proceso revolucionario en Costa Rica, si bien planteaban que en la construcción del socialismo era necesaria la hegemonía de la clase obrera y su ideología, esto no podía lograrse mediante maniobras ni imposiciones que dieran al traste con los esfuerzos por construir un bloque amplio, patriótico y democrático. A su vez, reconocían la debilidad numérica y política de este sector en Costa Rica y llamaban a prestar atención al papel revolucionario que la pequeña burguesía urbana y rural podía jugar en el país ("Camino pacífico", 1968). Es necesario tener presente que entre 1948 y 1975, el PVP permaneció en un estatus de ilegalidad por disposición del párrafo segundo del Artículo 98 de la Constitución Política de Costa Rica, promulgada posterior a la guerra civil que, en 1948, había perdido el bando de los comunistas, dando como resultado su proscripción. Entre otras consecuencias, esto le había impedido al partido participar como tal en procesos electorales de manera oficial, por lo que sostuvo una campaña permanente para lograr su vuelta a la legalidad.

Como señala Merino (1996), quien en las décadas de 1970 y 1980 fue parte del PVP, esta condición tuvo consecuencias en el plano organizativo e identitario de la organización. La situación de ilegalidad, aislamiento, marginalidad y exclusión que vivió el PVP en estos años le obligó a partir de la década de 1950 a implementar estrategias de trabajo clandestino, que a nivel interno tuvieron el efecto de restringir los espacios democráticos y de propiciar el surgimiento de una cultura sectaria, vertical y ortodoxa a nivel teórico y organizativo. No obstante, esto no hizo que el partido perdiera la flexibilidad táctica que había empezado a implementar desde mediados de la década de 1930, ni que abandonara la estrategia político-democrática como principal forma de lucha, manteniendo un carácter reformador, nacional y popular (Merino, 1996). Así, para 1968, el PVP se encontraba impulsando una importante campaña para poder participar en los comicios electorales de 1970 (Merino, 1996).

Por otro lado, de acuerdo con el mismo autor, es en esta misma década que los vínculos políticos e ideológicos con la Unión Soviética fueron reforzados a partir de la promoción de un importante proceso de formación de cuadros políticos en escuelas soviéticas, lo que para el autor tuvo como consecuencia la introducción de una formación dogmática en su entendimiento y aplicación de la teoría marxista, debilitando los esfuerzos nacionales de formación e interpretación del marxismo (Merino, 1996). Este proceso a su vez reforzó las tesis sostenidas por el PVP en contraposición a los movimientos guerrilleros que se desarrollaban en la región. Como señala Solís (1985), el PVP y Manuel Mora, como su principal ideólogo, entendían la revolución y la construcción del socialismo en general de manera "etapista". Esto implicaba un constante esfuerzo por caracterizar y dilucidar las etapas, fases y requisitos necesarios para avanzar en la construcción del socialismo. Bajo esta lógica, esencialmente positivista, el socialismo sería el resultado de un proceso evolutivo regulado por leyes naturales, mismas que regían el desarrollo de las sociedades. El realismo al cual aludía Mora de manera constante sería entonces el conocimiento preciso de la etapa correspondiente y de lo que era posible en cada etapa, de manera que no se fuera más allá y se diera al traste con todo el proceso evolutivo. 
Para Solís (1985), esta concepción desdibujaba a los actores y su agencia. La acción del partido consistía entonces en intervenir para el desarrollo necesario de cada etapa.

Durante el período de estudio, el PVP caracterizó a la etapa de la revolución que vivía Costa Rica como anti-feudal y antiimperialista. Además, entre las tareas principales en esta etapa se planteaban el desarrollo económico nacional, el impulso a la reforma agraria, y la defensa de la soberanía nacional y el régimen democrático. Esto le llevó a tener una concepción amplia de las fuerzas motrices de la revolución, donde cabía desde la clase obrera hasta capitalistas progresistas y patriotas, categorizados como burguesía nacional (Salom, 1987).

La coincidencia racional de los intereses de los grupos con los objetivos de la etapa en cuestión determinaría la adhesión de estos a las fuerzas motrices revolucionarias, reduciendo estos objetivos a una visión economicista de la historia. Así, la burguesía nacional, en tanto estaría interesada en el desarrollo económico nacional, debería colocarse del lado antiimperialista, al ser el imperialismo el principal lastre que impedía el desarrollo económico nacional de acuerdo con el pensamiento de Mora y el PVP. Así, la oposición imperialismo-antiimperialismo, desarrollo o subdesarrollo, funcionó como determinante de su política de alianzas (Solís, 1985). Se puede entonces plantear que los postulados ideológicos y programáticos del PVP iban en sintonía con los que el movimiento comunista latinoamericano sostenía en esta época.

De esta manera, desde finales de la década de 1950, pero con más claridad ya en la década de 1960, el PVP empezó a caracterizar al Partido Liberación Nacional (PLN) como un partido fundamentalmente progresista (Merino, 1996). Consideraba que la preponderancia numérica de la pequeño burguesía y burguesía nacional, entendidas como fuerzas democráticas, le daba mayores condiciones para hacerle frente al imperialismo, a diferencia de Unificación Nacional, partido que ligaban más claramente a la oligarquía imperialista. Así, a lo largo de todo el período de estudio, el PVP, y con mayor claridad Manuel Mora, albergó de manera permanente la esperanza de poder llegar a formar un bloque patriótico, democrático y antiimperialista con el PLN o con fuerzas internas de ese partido que rompieran con el imperialismo. Fue constante además la estrategia de buscar acercar a los llamados sectores democráticos de los demás partidos de la burguesía en general (Salom, 1987).

Para Solís (1985), esta coincidencia de tareas y objetivos con el PLN, planteada por el PVP y derivada de una concepción economicista del socialismo, redujo de manera importante su capacidad de establecer una posición crítica frente a esa organización y posicionarse como una alternativa política frente a la población. Para el sociólogo, para plantearse como una alternativa distinta era fundamental, a partir de la convicción de lo negativo del presente, elaborar la añoranza a algo distinto de lo que existía. Según Solís en el PVP esta elaboración fue débil a falta de una crítica elaborada de la democracia liberal costarricense que posibilitara posicionar con consistencia la necesidad de una democracia socialista que la superara. Como señala Merino (1996), para Mora la democracia era un instrumento de lucha que los comunistas costarricenses debían saber usar para construir el socialismo y no un instrumento de la burguesía o de dominación de clase. Era así, una democracia sin adjetivos. 
Como herramienta discursiva, Mora utilizó en este período de manera constante el llamado a frentes amplios que depusieran los intereses políticos particulares en aras de un interés nacional por defender la democracia costarricense, constantemente amenazada por el fascismo al servicio del imperialismo (Solís, 1985). Para Dobles y Leandro (2005), en Manuel Mora la política de alianzas que desplegó el PVP en la década de 1940 se volvió una añoranza constante, que lo llevó de manera sistemática a buscar en cada coyuntura reeditar el pacto social con los partidos de la burguesía nacional, principalmente con el PLN.

De acuerdo con Salom (1987), tanto el MRP como el PSC criticaban el rol que el PVP le daba a la llamada burguesía nacional dentro de las fuerzas motrices de la revolución. Ambos consideraban que no era viable que los intereses de este sector coincidieran con los del movimiento popular, privilegiando un análisis desde la categoría de clase social y no desde la oposición imperialismo-antiimperialismo. Asimismo, criticaban el llamado a la unidad con base en intereses de unidad nacional por sobre los intereses de clase. Consideraban que la unidad y el fortalecimiento de las fuerzas revolucionarias eran una condición previa indispensable para conformar un frente con sectores patrióticos y progresistas. En el plano regional, el FSLN fue parte del abanico de organizaciones guerrilleras surgidas a partir de la década de 1960 en América Latina para combatir a los regímenes militares y autoritarios que dominaban la región, en este caso particular, a la dinastía somocista que gobernó Nicaragua entre 1937 y 1979.

Como señala I Puig (2012), desde su fundación en 1961 por parte de jóvenes, en su mayoría estudiantes provenientes de sectores urbanos y medios disidentes del Partido Socialista de Nicaragua (PSN) y el Partido Conservador (PC), el FSLN se mantuvo como una organización que, bajo la influencia de la estrategia foquista popularizada por la guerrilla cubana, privilegió asentarse en las montañas del norte y centro de Nicaragua, desde donde organizó diversos intentos de incursión al interior del territorio nicaragüense, protagonizando intensos combates con la Guardia Nacional, principal bastión militar del régimen somocista, para luego replegarse nuevamente en las montañas y resistir fuertes oleadas de represión interna. Esto les obligaba a reorganizar de manera constante su dirección política a raíz del asesinato de varios de sus principales líderes en estas maniobras.

Si bien tuvo en su fundación una fuerte influencia de las bases teóricas del marxismo, vanguardismo, foquismo, la teología de la liberación y el nacionalismo antiimperialista, ideológicamente fue una organización flexible y pragmática, que incorporaba diversas corrientes de pensamiento compatibles con los objetivos de liberación nacional, incluidas influencias liberales y socialdemócratas, siendo así que no podía hablarse de una organización monolítica ni ortodoxa a nivel ideológico (I Puig, 2012). En este sentido, el nacionalismo, el antiimperialismo y el elemento antidictatorial jugaron un rol aglutinador importante frente a los matices y variaciones políticas internas y frente a la ausencia de un proyecto claro de sociedad para impulsar en el eventual escenario de una Nicaragua sin Somoza (Dore y Weeks, 1992).

Durante la década de 1960 el FSLN fue fundamentalmente una pequeña organización guerrillera ubicada en el centro y el norte de Nicaragua. La intensidad de 
los ataques emprendidos contra el pequeño núcleo guerrillero por parte de la Guardia Nacional de Nicaragua obligaba al FSLN a mantenerse recluido en las montañas y a la clandestinidad y fue sometido a constantes derrotas militares. A nivel cultural e identitario, se construyó en este periodo una fuerte mitología alrededor de "la montaña" como foco y espacio de la resistencia (I Puig, 2012). En estas condiciones, se forjó una organización altamente rígida, centralizada y jerárquica, en la que la Dirección Nacional ejercía un alto mando político y militar. El carácter clandestino de la organización implicó la adopción de una rígida disciplina por parte de su militancia, que en la década de 1960 rondó los 150 miembros y en su etapa de mayor expansión, luego de 1975, se acercó a 500 personas (I Puig, 2012). Durante la década de 1960 el FSLN experimentó entonces un importante aislamiento del resto de los sectores políticos antisomocistas, que en su gran mayoría apostaban por combatir al régimen por la vía institucional, un régimen que además aún no daba muestras de desgaste y gozaba del apoyo de un sector importante de la población (DeFronzo, 2007).

Hacia mediados de la década de 1970, el FSLN empezó a dar muestras de un importante cambio cualitativo en su estrategia, a la par de un importante desgaste político del régimen somocista impulsado por los efectos económicos y políticos del terremoto que destruyó Managua en 1972. Así, este cambio de estrategia se vio posibilitado por la radicalización de amplios sectores urbanos contra el régimen, lo que permitió a los sandinistas fortalecer su acción en las ciudades y penetrar en las organizaciones urbanas, rompiendo de manera paulatina el aislamiento político y geográfico característico de la década de 1960 . No obstante, el carácter poco sistemático de su accionar, producto de las dificultades del medio y de las diferencias en el interior de su organización, lo mantenían lejos de poder convertirse en una opción política viable para la mayoría de nicaragüenses (I Puig, 2012). Esto únicamente se volvió posible a raíz de una combinación de factores internos y externos en las etapas finales de la insurrección popular contra el régimen somocista entre 1977 y 1979.

Asimismo, las diferencias internas existentes en el FSLN se expresaron en el fraccionamiento de la dirección nacional en tres tendencias, entre 1975 y 1977 , que discrepaban en cuanto a la estrategia y sujetos del proceso revolucionario. La primera de ellas, denominada la Guerra Popular Prolongada (GPP), planteaba la necesidad de aferrarse a la estrategia foquista manteniendo la montaña como centro operativo de la guerrilla, desarrollando un trabajo de inserción de largo plazo entre los sectores rurales que permitiera finalmente derrocar a la dictadura. La segunda, la tendencia Proletaria o "Los Proletarios", postulaba la necesidad de trasladar la resistencia a las ciudades e integrar a las personas trabajadoras y a las organizaciones laborales en un plan de huelgas, movilizaciones urbanas y paros masivos contra el régimen que eventualmente condujeran a su caída. La tercera, la tendencia "Tercerista" o "Insurreccional", desplegó una estrategia destinada a integrar a sectores de la burguesía nicaragüense descontentos con el régimen a través de un planteamiento ideológico amplio que integraba elementos de la socialdemocracia y el cristianismo (DeFronzo, 2007). 
La amplitud y flexibilidad ideológica tercerista le permitió a la organización establecer una red de apoyos entre sectores de la burguesía nicaragüense y también costarricense, que en el momento más álgido de la lucha antisomocista, entre 1978 y 1979, fueron de gran importancia logística y material (Ortega, 2004). De esta manera, diferentes concepciones políticas convivieron dentro del FSLN cobijadas dentro del objetivo común de derrotar a la tiranía somocista. Estas diferencias alcanzaron su punto máximo en la división de su dirección política a mediados de la década de 1970 y pasaron nuevamente a un segundo plano durante la década de 1980 una vez que el sandinismo se volvió la fuerza hegemónica del nuevo gobierno nicaragüense, imponiendo una férrea disciplina militar en el marco de una intensa agresión contrarrevolucionaria coordinada por la administración estadounidense de Ronald Reagan (1981-1989). No obstante, esto no implicó la desaparición de las diferencias y discrepancias de fondo, que nuevamente pasaron a primer plano tras la derrota electoral del sandinismo en 1990.

\section{POLÉMICAS ENTRE "VIEJOS” Y "NUEVOS” REVOLUCIONARIOS (1966-1970)}

Si bien el período de cooperación oficial y coordinada entre el PVP y el FSLN se desarrolla en la etapa más intensa de la insurrección antisomocista entre 1977 y 1979 , es necesario indicar que los primeros acercamientos entre ambas organizaciones se dieron al poco tiempo de la fundación del FSLN. Durante este período inicial existieron contactos e intentos de establecer relaciones de cooperación entre el FSLN y movimientos de la izquierda costarricense, ya que parte del liderazgo sandinista como Carlos Fonseca Amador, veía a Costa Rica como la "retaguardia natural" del movimiento guerrillero nicaragüense (Ardón, 2017). No obstante, en estos primeros años fueron el MRP y PSC las organizaciones que de manera más activa colaboraron con el sandinismo por sus características ideológicas y organizativas.

El tipo de relación establecida entre las direcciones del PVP y el FSLN durante los primeros años estuvo permeado por las disputas y tensiones que se dieron en este período histórico entre partidos comunistas y organizaciones guerrilleras a nivel regional, a raíz de las diferencias existentes entre ambas organizaciones en cuanto a su estrategia reseñadas anteriormente. Sin embargo, como se pasará a ver, esto no impidió que se ensayaran en este período algunos momentos de cooperación y solidaridad, principalmente bajo el liderazgo de Fonseca Amador, que hacia finales de la década de 1960 se encontraba junto con otros miembros de la dirección sandinista en Costa Rica para reorganizar el movimiento que había sido brutalmente reprimido luego de los primeros intentos guerrilleros, como el de Pancasán en 1967. Fue entre 1968 y 1969 que este grupo dirigente redactó el "Programa Histórico" y los Estatutos del FSLN (Baltodano, 2010, p.26). 
Sergio Érick Ardón Ramírez, perteneciente en ese momento a una de las organizaciones costarricenses que de manera más activa y decidida colaboraba con el FSLN, el MRA (posteriormente MRP), relata que entre sus tareas se encontraba garantizar lugares seguros para que la dirigencia sandinista pudiera reunirse y deliberar sus tesis, para lo cual les facilitó la hacienda Siquiares en Alajuela. Posteriormente colaboró en facilitar su reingreso a Nicaragua en la clandestinidad. Fue un periodo según relata Ardón (2013), en el que la mayoría del tiempo y recursos de la joven organización se utilizaron para colaborar con el sandinismo. De manera más modesta y reservada, y aún en la ilegalidad, la dirigencia del PVP también empezaba a colaborar con los jóvenes sandinistas, siempre manteniendo un tono bastante paternal, como evidencia la correspondencia mantenida entre 1966 y 1970 por Manuel Mora Valverde, quien fungía como secretario general del PVP desde su fundación en 1931, y Carlos Fonseca Amador, joven fundador y dirigente del FSLN.

A partir de la lectura de la misma es notable el interés que tenía Fonseca en conseguir el apoyo de los vanguardistas para gestionar recursos económicos y materiales que le permitieran a su organización desarrollar su actividad revolucionaria con más solvencia. Fonseca estaba interesado en las redes y conexiones que los comunistas costarricenses mantenían con el movimiento comunista internacional, principalmente con la Unión Soviética. De esta manera, fue constante la solicitud de interponer "sus buenos oficios" para tal propósito. En este sentido se dirigió el joven líder sandinista a Mora Valverde en setiembre de 1966:

\section{Estimado amigo:}

En mis manos se encuentra su papelito con fecha 3 de los corrientes. Hubiéramos querido que ud se refiriera a un punto muy importante para nosotros, $\mathrm{y}$ el cual tocamos en la carta que le mandamos con fecha 30 de julio del corriente año. Se trata el punto, de la solidaridad material que uds pueden obtener para atender nuestra situación...Deseamos obtener por medio de uds una solidaridad seria y columniosa [sic], que contribuya efectivamente a que salgamos de esta vergüenza. (Archivo Nacional de Costa Rica, 1966)

En esta misma misiva podemos constatar la existencia de importantes ayudas monetarias previas por parte del PVP hacia Fonseca para la actividad que el FSLN desplegaba en Nicaragua en ese momento. Asimismo, era evidente el esfuerzo de Fonseca para legitimar la "madurez" de su organización y su estrategia frente a los cuestionamientos del veterano líder vanguardista en ese aspecto. De esta manera recalcó:

\footnotetext{
Aunque no son muchas en nuestro concepto las pruebas por las que hemos pasado en estas empresas, sí creemos que son suficientes para que nos hayan curado de entusiasmos infundados, y cuando decimos que podemos tener éxito, es porque alguna razón debemos tener. (Archivo Nacional de Costa Rica, 1966)
}

En este sentido, los intercambios entre Fonseca y Mora eran también aprovechados por ambos para debatir de manera abierta sus distintas interpretaciones sobre la estrategia que debían desarrollar las fuerzas revolucionarias nicaragüenses para 
combatir al régimen somocista. Esto lo podemos nuevamente constatar en la nota enviada por Mora a Fonseca el 27 de julio de 1967:

Amigo y camarada:

En ningún momento me he negado a conversar con $\mathrm{Ud}$. Talvez no fue posible que nos viéramos en dos oportunidades señaladas por Ud. sin previa consulta conmigo. Pero la culpa no fue mía sino de la lucha en que estoy metido.

Sin embargo hemos conversado con alguna amplitud y yo le he hablado con amplitud y con mucha claridad. Con hechos y no con palabras le hemos demostrado a usted que lo queremos y estimamos en lo personal. Y con razones le hemos explicado nuestras discrepancias. Me atrevo a afirmar que esas discrepancias no están en la sustancia de nuestra lucha sino en la forma de llevarla de a cabo. Nosotros no creemos que las armas solas puedan hacer milagros. La revolución tiene que ser obra de las masas consientes. El FS no logrará botar a Somoza si no logra de antemano que las masas populares respalden su acción armada. Le ofrezco toda la ayuda de mi Partido y la mía personal para luchar por la movilización de las masas populares de Nicaragua. También se la ofrezco para preparar la acción armada que es indispensable en Nicaragua, cosa que nunca hemos negado. Las masas necesitan un brazo armado para tumbar a una satrapía apuntalada por el imperialismo. Le resumo a vuela máquina, porque dispongo de poco tiempo, el plan de movilización de masas que le ofrecí. Lo abrazo y espero su respuesta (Archivo Nacional de Costa Rica, 1967a).

Como se desprende de lo anterior, si bien Mora consideraba que la estrategia armada no era aplicable al contexto costarricense, en este momento ya no negaba la validez de la vía armada en la lucha contra la dictadura somocista en Nicaragua, e incluso de manera explícita ofreció su colaboración para preparar las condiciones para la misma. El veterano líder sí se mostraba escéptico frente a la efectividad de la estrategia foquista, implementada en este periodo por el FSLN, que como vimos, le mantenía en un estado de aislamiento en las montañas del centro y norte del país con enormes dificultades para vincular su accionar con las organizaciones populares urbanas. Para Mora, era fundamental romper con ese aislamiento y desarrollar una estrategia amplia que lograra un apoyo popular y masivo en las ciudades a la lucha revolucionaria.

Sin embargo, desde la década de 1940 el PVP había sido cauteloso alrededor de la vía armada en Nicaragua. Pensaba que no estaban dadas las condiciones para garantizar un triunfo revolucionario mediante esa estrategia ante la falta de apoyo en las ciudades y organizaciones obreras. Consideraba además que el Partido Socialista Nicaragüense (PSN), su homólogo y principal referente político en Nicaragua, no tenía en ese momento la capacidad de ponerse a la cabeza de un proceso insurreccional de carácter masivo, por lo que este podía terminar siendo liderado la oposición conservadora a Somoza. Por otro lado, consideraba que el somocismo mantenía un amplio respaldo popular y el apoyo compacto de la Guardia Nacional (Archivo Nacional de Costa Rica, s.f.). 
Así, el PVP había optado por apoyar la estrategia sostenida por el PSN, que consistía en aprovechar los breves momentos de apertura democrática del régimen para intentar incidir desde el ámbito político electoral sin dejarse arrastrar "ni por las críticas de los grupos afines extremistas, prochinos, ni por el temor de que una actitud realista suya sea interpretada como traición al antisomocismo" (Archivo Nacional de Costa Rica, s.f.). Como un recurso de autoridad frente a sus homólogos nicaragüenses, el PVP apeló a su experiencia en la guerra civil de 1948:

\begin{abstract}
Nuestro caso en Costa Rica debe servir de ejemplo en estos momentos para los compañeros nicaragüenses. Nosotros, por un error de táctica, porque impulsamos en vez de detener la guerra civil en momentos en que la situación internacional no daba base para pensar en una guerra civil victoriosa para nosotros, perdimos en un mes todas nuestras posiciones y hemos necesitado dieciocho años para reconquistarlas apenas parcialmente. Con el agravante de que gentes cuyo criterio tomamos muy cuenta para cometer el error, después nos culparon de lo ocurrido, pero ya frente a un desastre que nosotros estuvimos obligados a prever. Lo mismo puede ocurrirles ahora a los camaradas nicaragüenses. $\mathrm{Si}$ previendo el desastre se pliegan al criterio de supuestos aliados o de extremistas pequeño-burgueses, cuando se produzcan los hechos serán atacados y culpados por los mismos que hoy están empujándolos a una posición equivocada. (Archivo Nacional de Costa Rica, s.f.)
\end{abstract}

Esta posición contraria a la vía armada parece entonces haber dominado las consideraciones del PVP sobre la lucha en Nicaragua hasta la década de 1960. Es hacia finales de esta década que comenzó a matizarse levemente al reconocer la necesidad de las armas para derrocar al régimen, si bien aún consideraba que no estaban dadas las condiciones para triunfar por esta vía sin antes haber logrado un apoyo masivo a la lucha antisomocista fruto de un amplio trabajo político.

Un hecho que pudo haber contribuido en este viraje en cuanto a su postura frente a la estrategia de lucha en Nicaragua fue la brutal masacre que el régimen somocista emprendió el 22 de enero de 1967 en contra de la oposición electoral, la Unión Nacional Opositora (UNO) liderada por los conservadores Pedro Joaquín Chamorro y Fernando Agüero, en plena ciudad capital cobrando la vida de centenares de personas, hecho que vino a radicalizar a muchos sectores políticos que aún creían en la posibilidad de combatir al régimen por la vía electoral. Como indica Mónica Baltodano (2010), quien fue militante sandinista en las décadas de 1970 y 1980, una primera división interna en el PSN se produjo a raíz de este hecho, que condujo a un sector de este partido a decantarse de manera decidida por la lucha armada y a fundar las Fuerzas Armadas Revolucionarias Nicaragüenses (FARN) de corta duración.

Así, este evento pudo haber influido también para que Mora reconociera la vía armada como una estrategia necesaria para luchar contra el somocismo y su Guardia Nacional y, a pesar de que su principal referente político en Nicaragua siguió siendo el PSN, diera algún crédito a la línea política que impulsaban Fonseca y los suyos, si bien aún sostenía la inviabilidad del triunfo únicamente por las armas sin un amplio trabajo político con otros sectores políticos y sociales. 
Por su parte, Fonseca veía con buenos ojos las sugerencias y consejos del líder comunista como consta en la misiva que envió el 30 de julio de 1967. Sin embargo, nuevamente reclamó que para poder desarrollar una red de trabajo en las principales ciudades del país y ampliar su apoyo popular, tal como sugería Mora, requerían de una cantidad de dinero y recursos que actualmente no poseían e insistía: "Con el respaldo de la autoridad de uds podríamos hacer gestiones para resolver ese problema económico. Nosotros no hemos querido acudir aun a nadie más riesgoso" (Archivo Nacional de Costa Rica, 1967b).

Así, si bien es posible notar un estira y encoje permanente entre ambos, lo cierto es que se venía construyendo una relación de cooperación aun marcada por momentos de desconfianza, que fue truncada momentáneamente luego de los sucesos de 1969 y 1970, provocados en buena medida por las urgencias financieras de los sandinistas. El 31 de agosto de 1969 Fonseca fue capturado en la provincia de Alajuela, luego de que un comando sandinista llevara a cabo un asalto a la sucursal del Banco Nacional en la Uruca, en San José, precisamente con el fin de obtener fondos para financiar las acciones de lucha en ese país y trasladar a la dirigencia sandinista, que se encontraba en Costa Rica, de regreso a Nicaragua. Si bien Ardón indica que Fonseca no fue parte del comando que llevó adelante el asalto, el gobierno de José Joaquín Trejos Fernández (1966-1970), del Partido Unificación Nacional, inició la captura de los principales dirigentes sandinistas que se encontraban en el país.

Ante esto, el PVP publicó una nota en el semanario Libertad en defensa de la inocencia del joven Fonseca, caracterizándolo como un joven valiente e idealista, proveniente de una familia con amplios recursos y entregado de lleno a una vida austera, sacrificial, despojada de bienes materiales, consagrada enteramente a la lucha revolucionaria. Así, si bien reconocía que no compartía enteramente su concepción de la lucha revolucionaria, daba fe de las nobles cualidades de Fonseca, que lejos de ser un bandolero, tal como lo presentaban los agentes de Somoza, era un auténtico y noble revolucionario ("Fonseca Amador", 1969, portada).

Era evidente el tono paternalista con el que se hacía referencia a Fonseca, quien para ese entonces tenía 33 años de edad, en un momento en que además se temía que el gobierno de Trejos Fernández, que mantenía buenas relaciones con Somoza, procediera a facilitar su extradición a Nicaragua para que cayera en manos de la Guardia Nacional. El PVP "inventó" además un origen acaudalado de Fonseca como estrategia para disipar las sospechas sobre su posible participación en un asalto bancario.

Así, los vanguardistas hicieron un llamado a todas las fuerzas democráticas del país a dejar de lado diferencias ideológicas, evitar que el joven sandinista fuera entregado a manos del régimen somocista y a velar para que fuera juzgado en tribunales costarricenses, apelando al sentimiento antisomocista que ya existía en una buena parte de la población nacional ("Fonseca Amador", 1969, portada). 
Desde su reclusión en la Penitenciaría de Alajuela, Fonseca agradeció las muestras de solidaridad dadas por los vanguardistas, a la vez que les reprochó no estar haciendo lo suficiente por apoyar la lucha del pueblo nicaragüense. Calificó a su líder, Manuel Mora Valverde, como parte de "la vieja generación revolucionaria", que si bien era valiosa, se mostraba conservadora frente a las nuevas condiciones de lucha en América Latina. En este sentido escribió Fonseca a Mora desde su celda. En esta comunicación, luego de agradecer y reconocer las muestras públicas de apoyo por parte del PVP hacia su persona, nuevamente increpó a los comunistas por, a su criterio, no estar haciendo lo suficiente por apoyar la lucha del pueblo y la juventud nicaragüense contra el gobierno de Somoza (Archivo Nacional de Costa Rica, 1969).

En este sentido, si bien reconocía del derecho de los comunistas a discrepar y mantener sus reservas frente a elementos de la estrategia que desplegaba el sandinismo, se mostró decidido a aumentar el reconocimiento que ya Mora en anteriores cartas había mostrado hacia la necesidad de la lucha armada para derrotar a Somoza:

\footnotetext{
Mis palabras, estimado camarada M. no se proponen hacer cambiar su punto de vista acerca de nuestra visión de la ruta a seguir para alcanzar la liberación. Lo que sin duda puedo proponerme es fortalecer el reconocimiento que Ud. personalmente ha expresado acerca de nuestra decisión.

En la actualidad nuestra organización enfrenta serios problemas materiales para los cuales con la mediación de Ud, puede lograrse una contribución a fin de que sean resueltos.

¿No cree Ud. que es una obligación moral que se nos respalde, aun de parte de sectores que no están plenamente convencidos de la corrección de nuestro método? ¿No cree Ud. que en el caso de que suframos nuevos golpes duros, alguna culpa le corresponderá a quienes pudiendo respaldarnos no quisieron hacerlo? (Archivo Nacional de Costa Rica, 1969)
}

El reclamo de Fonseca a Mora no era solo al líder comunista, sino a todo el movimiento comunista regional que este representaba y que había optado fundamentalmente por darle la espalda y criticar a la guerrilla nicaragüense por sus diferencias en cuanto a la estrategia armada. Fonseca se mostró enfático nuevamente en la necesidad de un mayor apoyo financiero y material por parte de los comunistas hacia la lucha del pueblo nicaragüense, que tenía en frente a una poderosa Guardia Nacional, principal sostén militar del régimen somocista. No obstante, era palpable un mayor acercamiento entre ambos dirigentes, a partir de una relación de respeto mutuo y de colaboración, si bien aún tímida por parte del líder comunista hacia Fonseca.

El tono entre ambos cambió unas semanas después, luego de que entre la noche del 23 y la madrugada del 24 de diciembre de 1969 un comando sandinista, liderado por Humberto Ortega Saavedra, intentó liberar a Fonseca de la prisión de Alajuela con un saldo de un guardia civil costarricense fallecido y otros tantos heridos. La operación fue un fracaso rotundo, ya que no solo generó el rechazo unánime de la población al asesinato del oficial costarricense, sino que todos los miembros del comando, incluido Fonseca, fueron capturados y enviados a la Penitenciaría Central bajo máxima seguridad (Ardón, 2017). 
Dentro de la lógica de pensamiento conspirativo de Mora, ese hecho fue interpretado como parte de una conjura protagonizada por fuerzas infiltradas de la derecha, destinada a sembrar una oleada de violencia anticomunista en el país en el marco de las elecciones que se iban a realizar en febrero de 1970 y sabotear la participación política de la izquierda, que aún en la ilegalidad participaba en los comicios con el Partido Acción Socialista (PASO) del ex liberacionista Marcial Aguiluz Orellana, y llevaba a Manuel Mora Valverde como diputado al primer lugar por San José. Según Mora, esas fuerzas desestabilizadoras de la derecha se aprovecharon "de la vanidad" del joven Fonseca para llevar a cabo el innecesario operativo, ya que era muy posible que este quedara pronto en libertad por la vía legal. De esta manera, se apresuró a condenar y rechazar públicamente la acción llevada a cabo por el comando sandinista ("Siniestro plan", 1970, pp.3-4).

El tono de Mora molestó profundamente a Fonseca, quien procedió a publicar, con la ayuda del PRA (posteriormente MRP), un largo recuento de las diferencias históricas entre los movimientos revolucionarios nicaragüenses y Vanguardia Popular, remitiéndose hasta las críticas esbozadas en su momento por el PVP a la estrategia desarrollada por Augusto César Sandino en la década de 1930 en su lucha contra la ocupación de los marines estadounidenses. Asimismo, retomó la crítica elaborada en la década de 1940 por el PVP en contra de la oposición conservadora a Somoza por querer combatir al régimen por la vía armada en lugar de aprovechar los espacios democráticos que este ofrecía, tal como proponía el PSN, y culminó con las diferencias más recientes entre el FSLN y el PVP. Finalmente, calificó a los vanguardistas como "falsos revolucionarios", "browderistas", y “pseudo marxistas" (Archivo Nacional de Costa Rica, 1970).

Como señala Ardón, quien en ese momento colaboraba con la seguridad de Fonseca en Costa Rica, el fracaso del operativo para liberar a Fonseca se debió fundamentalmente a la inexperiencia de la mayoría de sus jóvenes ejecutores, y no fue parte de conspiración alguna contra el PVP. Este tipo pensamiento conspirativo en la dirección del PVP, y en particular en Manuel Mora, estaba fundamentalmente asociado al modelo estalinista de partido que había adoptado desde la década de 1930.

Según Ardón, si bien Fonseca podría haber sido liberado por la vía legal, el comando actuó motivado por el temor de que el gobierno de Trejos Fernández decidiera montar algún operativo conjunto con Somoza para desaparecer a Fonseca de la cárcel de Alajuela. Este temor aumentó luego de la reunión sostenida unos días antes entre ambos mandatarios, por lo que decidieron proceder al operativo y proteger la vida del líder sandinista. La operación debía ser limpia y sin pérdidas humanas, sin embargo, la inexperiencia del joven comando que estuvo a cargo de la operación determinó el rumbo trágico que tomaron los acontecimientos (Ardón, 2017).

Unos meses después, el 21 de octubre de 1970, un comando sandinista esta vez liderado por Carlos Agüero Echeverría logró liberar a Fonseca, Humberto Ortega y demás líderes sandinistas presos en Costa Rica. Esto se logró mediante el secuestro de un avión de LACSA, recién iniciando el segundo gobierno de José Figueres Ferrer (19701974) del Partido Liberación Nacional y enemigo público de Somoza. Figueres accedió a canjear la liberación de los 24 pasajeros de la aeronave por los presos sandinistas. 
Ya en libertad, Fonseca y los demás fueron conducidos a La Habana, luego de pasar por México. Fonseca permaneció exiliado en Cuba hasta 1975, cuando volvió a Nicaragua para adentrarse de nuevo en la montaña, siendo finalmente asesinado por la Guardia Nacional un año después, en 1976, en la selva de Zinica a la edad de 40 años (Baltodano, 2010).

Durante la mayor parte de la década de 1970, las relaciones entre el PVP y el FSLN siguieron marcadas por las contradicciones y las diferencias en cuanto a la estrategia y su concepción de la lucha revolucionaria. Durante estos años, marcados por la división de la dirección nacional sandinista luego de 1975, la línea sostenida hacia los sandinistas por parte del PVP fue la de escuchar y dialogar siempre con sus miembros, sin adscribirse o decantarse por ninguna de las tres tendencias en particular, sosteniendo su disposición de brindar apoyo y solidaridad a la lucha por la liberación de Nicaragua, pero marcando siempre que sus relaciones oficiales con los revolucionarios nicaragüenses serían con el PSN y su juventud (Archivo Nacional de Costa Rica, 1967-1979).

No obstante, esto empezó a cambiar con el surgimiento de la tendencia tercerista o insurreccional del FSLN y su radicación en Costa Rica como centro de operaciones y retaguardia política entre 1976 y 1977. Es con esta tendencia, liderada entre otros por los hermanos Ortega con quienes Mora desarrolló mayores coincidencias alrededor de su estrategia y concepción amplia de la lucha antisomocista y con quienes finalmente se decidió a brindar un apoyo más decidido a través de la Comisión Nacional de Seguridad (CNS) del PVP, que en su etapa cúspide se expresó en el envío de una brigada de militantes vanguardistas a combatir junto con las fuerzas sandinista en el Frente Sur en julio de 1979 y que luego de la caída del régimen somocista, realizó una importante colaboración en la formación del nuevo Ejército Popular Sandinista (EPS) entre los meses de julio y diciembre de 1979 (Cortés, 2018).

\section{CONCLUSIONES}

Los primeros contactos entre el FSLN y el PVP se desarrollaron desde la década de 1960. En esta primera etapa las relaciones entre las direcciones políticas de ambas organizaciones se enmarcaron en las discusiones y debates que a nivel general se desarrollaban en ese momento a lo largo de toda América Latina entre la izquierda comunista y la denominada "nueva izquierda". A partir del triunfo revolucionario cubano en 1959, una generación de jóvenes urbanos de clase media e intelectuales se radicalizaron y abrazaron el método popularizado y sistematizado por Fidel Castro Ruz y Ernesto Guevara de la Serna. Esta juventud se organizó en movimientos guerrilleros a lo largo de la región con el objetivo de derrocar a los regímenes militares que gobernaban la mayoría de países del área, y de acceder al poder por la vía armada, abandonando así las filas de los Partidos Comunistas latinoamericanos que por el contrario habían optado por tratar de aprovechar las ventanas democráticas que en ocasiones abrían las dictaduras para combatirlas desde el terreno 
político institucional, privilegiando la "vía pacífica hacia el socialismo", estrategia que contaba con el aval de la Unión Soviética y que era calificada de conservadora por parte de las guerrillas, incluida la del FSLN.

En este marco, el joven Carlos Fonseca Amador, principal dirigente del FSLN hacia finales de la década de 1960, vio en Manuel Mora Valverde y su partido, a los representantes de esa vieja generación de comunistas, valiosa pero conservadora, mientras que Mora y los vanguardistas vieron en el joven dirigente sandinista al representante de una juventud valiente pero pequeñoburguesa, aventurera y extremista que por más buenas intenciones no iba a lograr derrotar a la tiranía somocista únicamente con rifles sin una correcta estrategia de lucha de masas. De esta manera, discreparon sobre la estrategia correcta para derrocar a la satrapía somocista e instaurar un régimen democrático en Nicaragua.

En este período, el principal referente político del PVPen Nicaragua fue el Partido Socialista Nicaragüense, partido comunista que hasta 1976 privilegió la vía institucional como principal estrategia para combatir al régimen somocista. Ese año sufrió una nueva división entre un sector que comenzó a decantarse por la vía armada e insurreccional, y otro que se mantuvo en oposición y desaprobación de las formas violentas de lucha que lideraba el FSLN. Es por esto que los contactos más fuertes que hizo el sandinismo en el país en la década de 1960 fue con las organizaciones que nacieron dentro de la llamada "nueva izquierda" en Costa Rica, críticas del socialismo soviético e influenciadas por el modelo cubano como el MRA (posteriormente MRP) y el PSC.

Si bien Manuel Mora Valverde accedió a colaborar de manera temprana con la lucha sandinista y el joven Fonseca en el plano económico y político, esta colaboración fue tímida y estuvo marcada por un fuerte tono paternal por parte de veterano comunista hacia el joven sandinista, expresión de las divergencias generacionales de los movimientos revolucionarios de la época. Fue hasta la aparición de la tendencia tercerista del FSLN, entre 1976 y 1977, que Mora se decidió a brindar un apoyo más contundente, en este caso, a la estrategia insurreccional promovida por los terceristas, quienes abogaban por la construcción de un amplio bloque antisomocista que abarcara desde sectores de la burguesía nicaragüense hasta los sectores campesinos y obreros. No obstante, las relaciones entre vanguardistas y sandinistas fueron siempre complejas, cargado de tensiones, desconfianzas mutuas y discrepancias, pero también de coincidencias, siendo la principal la necesidad de derrotar a la dictadura somocista e instaurar un nuevo gobierno en Nicaragua.

\section{AGRADECIMIENTOS}

Este artículo es resultado de una tesis de Maestría Académica en Historia escrita en el Programa de Posgrado en Historia de la UCR. Agradezco a la Vicerrectoría de Investigación de la Universidad de Costa Rica por haber apoyado esta investigación a través del Fondo de Apoyo a Tesis de Posgrado durante el año 2018. 


\section{REFERENCIAS}

Archivo Nacional de Costa Rica. Fondo Manuel Mora Valverde. (1966). Correspondencia entre Manuel Mora Valverde y Carlos Fonseca Amador. San José: Archivo Nacional de Costa Rica.

Archivo Nacional de Costa Rica. Fondo Manuel Mora Valverde. (1967a). Correspondencia entre Manuel Mora Valverde y Carlos Fonseca Amador. San José: Archivo Nacional de Costa Rica.

Archivo Nacional de Costa Rica. Fondo Manuel Mora Valverde. (1967b). Correspondencia entre Manuel Mora Valverde y Carlos Fonseca Amador. San José: Archivo Nacional de Costa Rica.

Archivo Nacional de Costa Rica. Fondo Manuel Mora Valverde. (1967-1979). Expediente sobre la Juventud Vanguardista Costarricense. San José: Archivo Nacional de Costa Rica.

Archivo Nacional de Costa Rica. Fondo Manuel Mora Valverde. (1969). Correspondencia entre Manuel Mora Valverde y Calos Fonseca Amador. San José: Archivo Nacional de Costa Rica.

Archivo Nacional de Costa Rica. Fondo Manuel Mora Valverde. (1970). Respuesta de Carlos Fonseca Amador a "Columna Subversiva" de Libertad, Penitenciaría Central. San José: Archivo Nacional de Costa Rica.

Archivo Nacional de Costa Rica. Fondo Manuel Mora Valverde. (s.f.). Síntesis de un cambio de impresiones sobre la situación política de Nicaragua habido en el Secretariado Ejecutivo del Comité Central del Partido Vanguardia Popular. San José: Archivo Nacional de Costa Rica.

Ardón Ramírez, S.E. (2013) A la frontera como en 1856. En J. Picado Lagos (Ed.), Los Amigos venían del Sur (pp.3-10) San José: EUNED.

Ardón Ramírez, S.E. (27 de febrero 2017) El Asalto. Julia Ardón. Recuperado de http://juliaardon.net/ otras-miradas/el-asalto/

Baltodano Marcenaro, M. (Ed.) (2010) Memorias de la lucha sandinista. De la forja de la vanguardia a la montaña. Managua: INHCA-UCA.

Camino pacífico de la revolución. (1968, marzo 16) Libertad, p.5.

Cortés Sequeira, S. (2018) Entre la esperanza y la desilusión: La izquierda costarricense y la Nicaragua Sandinista (1979-1992) (Tesis de Maestría Académica en Historia). Universidad de Costa Rica, Costa Rica.

DeFronzo, J. (2007) Revolution and Revolutionary Movements. New York: Taylor \& Francis Group.

Dobles Oropeza, I. y Leandro Zúñiga, V. (2005) Militantes. La vivencia de lo político en la segunda ola del marxismo en Costa Rica. San José: EUCR.

Dore, E. y Weeks, J. (1992) The Red and the Black: The Sandinistas and the Nicaraguan Revolution. Londres: Institute of Latin American Studies. 
Figueroa Ibarra, C. y I Puig, S.M. (Eds.) (2006) La izquierda revolucionaria en Centroamérica. De la lucha armada a la participación electoral. Madrid: Los libros de la Catarata.

Fonseca Amador no es un bandolero. (1969, setiembre 6) Libertad, portada.

Gould, J.L. (2009) Solidarity under Siege: The Latin American Left, 1968. The American Historical Review, Vol. (114), 348-375. Recuperado de https://doi.org/10.1086/ahr.114.2.348

I Puig, S.M. (2012) Nicaragua (1979-199) La revolución enredada. Madrid: Libros de la Catarata.

Merino del Río, J. (1996) Manuel Mora y la democracia costarricense. Viaje al interior del Partido Comunista. Heredia: Editorial Fundación Universidad Nacional.

Molina Jiménez, I. y Díaz Arias, D. (2017) El verdadero anticomunismo. Política, género y Guerra Fría en Costa Rica (1948-1979). San José: EUNED.

Ortega Saavedra, H. (2004) La epopeya de la insurrección. Managua: Lea Grupo Editorial.

Rey Tristán, E. (2016) Del etapismo a la inmediatez. Debates en torno a la idea de revolución en América Latina a partir de 1959. SÉMATA, Ciencias Sociais e Humanidades, (28), 363-388. Recuperado de https://doi.org/10.15304/s.28.3752

Salom Echeverría, R. (1987) La crisis de la izquierda en Costa Rica. San José: Porvenir.

Siniestro plan para introducir violencia en Costa Rica. (1970, enero 10) Libertad, pp.3-4.

Solís Avendaño, M. (1985) La crisis de la izquierda costarricense: consideraciones para una discusión. San José: CEPAS.

Torres Rivas, E. (2008) Centroamérica: de la izquierda revolucionaria a la izquierda socialdemócrata. Quórum, 41-50. 